\title{
Paraarticular osteochondroma of a cervico-thoracic facet joint presenting as myelopathy.
}

\section{$\operatorname{AUTHOR}(S):$}

Okamoto, Takeshi; Neo, Masashi; Fujibayashi, Shunsuke; Takemoto, Mitsuru; Nakamura, Takashi

\section{CITATION:}

Okamoto, Takeshi ...[et al]. Paraarticular osteochondroma of a cervico-thoracic facet joint presenting as myelopathy.. Skeletal radiology 2011, 40(12): 1629-1632

\section{ISSUE DATE:}

2011-12

URL:

http://hdl.handle.net/2433/151710

\section{RIGHT:}

The final publication is available at www.springerlink.com; This is not the published version. Please cite only the published version.; この論文 は出版社版でありません。引用の際には出版社版をご確認ご利用くだ さい。 


\section{Editorial Manager(tm) for Skeletal Radiology Manuscript Draft}

\section{Manuscript Number:}

Title: Paraarticular osteochondroma of the spine presenting as myelopathy: case report

Article Type: Case Report

Keywords: Osteochondroma; Paraarticular osteochondroma; Soft tissue neoplasms; myelopathy

Corresponding Author: Takeshi Okamoto, M.D., Ph.D.

Corresponding Author's Institution: Kyoto University Graduate School of Medicine

First Author: Takeshi Okamoto, M.D., Ph.D.

Order of Authors: Takeshi Okamoto, M.D., Ph.D.;Masashi Neo, M.D., Ph.D.;Shunsuke Fujibayashi, M.D., Ph.D.;Mitsuru Takemoto, M.D., Ph.D.;Takashi Nakamura, M.D., Ph.D.

Abstract: Paraarticular ostehochondroma is a rare osteocartilagenous tumor that arises in the soft tissue adjacent to a joint with no attachment to the bone. Although several case reports have been published on this tumor, spinal paraarticular osteochondroma has not been reported in the literature. We present a patient with a paraarticular osteochondroma arising in the spinal canal just medial to the facet joint that caused severe spinal cord compression. A 69-year-old man complained of paresthesia and muscle weakness in the lower extremities. Cervical magnetic resonance imaging and computed tomography revealed an intraspinal mass lesion at C7-Th1 with severe compression of the thecal sac, and concomitant spinal canal stenosis on C3-C7. Surgical en bloc resection of the calcified mass and C3C6 laminoplasty were performed. The patient's symptom improved dramatically. Histological analysis showed that the lesion comprised trabecular bone and bone marrow, and was capped by hyaline cartilage with no connection to the bone. This is the first report of spinal paraarticular osteochondroma.

Suggested Reviewers: 
1 Paraarticular osteochondroma of the spine presenting as myelopathy:

4 Takeshi Okamoto $^{1}$ MD, PhD, Masashi Neo ${ }^{1}$ MD, PhD, Shunsuke Fujibayashi ${ }^{1}$ MD,

$5 \quad$ PhD, Mitsuru Takemoto ${ }^{1}$ MD, PhD, Takashi Nakamura ${ }^{1}$ MD, PhD

6

$7{ }^{1}$ Department of Orthopaedic Surgery, Graduate School of Medicine, Kyoto University,

8 Kyoto City, Japan

9

10 Corresponding Author:

11 Takeshi Okamoto

12 Department of Orthopaedic Surgery, Kyoto University Graduate School of Medicine,

1354 Kawahara-cho, Shogoin, Sakyo-ku, Kyoto 606-8507, Japan

14 Tel: $+81-75-751-3362$

15 Fax: +81-75-751-8409

e-mail: okaken@kuhp.kyoto-u.ac.jp 
Spinal paraarticular osteochondroma

\begin{abstract}
Paraarticular ostehochondroma is a rare osteocartilagenous tumor that arises in the soft tissue adjacent to a joint with no attachment to the bone. Although several case reports have been published on this tumor, spinal paraarticular osteochondroma has not been reported in the literature. We present a patient with a paraarticular osteochondroma arising in the spinal canal just medial to the facet joint that caused severe spinal cord compression. A 69-year-old man complained of paresthesia and muscle weakness in the lower extremities. Cervical magnetic resonance imaging and computed tomography revealed an intraspinal mass lesion at $\mathrm{C} 7-\mathrm{Th} 1$ with severe compression of the thecal sac, and concomitant spinal canal stenosis on C3-C7. Surgical en bloc resection of the calcified mass and C3-C6 laminoplasty were performed. The patient's symptom improved dramatically. Histological analysis showed that the lesion comprised trabecular bone and bone marrow, and was capped by hyaline cartilage with no connection to the bone. This is the first report of spinal paraarticular osteochondroma.
\end{abstract}


Spinal paraarticular osteochondroma

\section{Introduction}

Conventional osteochondroma is the most common type of benign bone tumor $[1,2]$. It usually originates near the end of a long bone, and sometimes grows away from the joint. A osteochondroma is characterized by an osseous component capped by cartilage, and is connected to bone by a stalk [3]. Spinal osteochondroma comprises only $3 \%$ of solitary osteochondroma but may cause spinal cord compression [4-6]. A paraarticular or juxtaarticular ostehochondroma is a rare osteocartilagenous tumor that arises in the soft tissue adjacent to a joint without attachment to bone [2, 3, 7]. Although several case reports have described paraarticular ostehochondromas, all of the lesions reported were adjacent to the joints of the extremities, most of which involved the knee region $[3,8]$. To our knowledge, no case of spinal paraarticular ostehochondromas has been reported.

In this report, we present a patient with a paraarticular osteochondroma arising in the spinal canal just medial to the facet joint that caused severe spinal cord compression.

\section{Case presentation}

History. A 69-year-old man presented with paresthesia and muscle weakness in both lower extremities. He was referred to our hospital with a diagnosis of cervical spondylotic myelopathy. He occasionally stumbled when walking over slightly irregular 
Spinal paraarticular osteochondroma

surfaces, and had difficulty in walking up and down stairs. The symptoms were noticed one month before the consultation and then deteriorated rapidly. He had no history of osteochondroma in the extremities.

Examination. His gait was spastic with a wide base, and tandem gait was unstable. His tendon reflexes were normal in the upper extremities and hyperactive in the lower legs with sustained ankle clonus. The Babinski sign was positive bilaterally. He had no clumsiness of the hands. Mild motor weakness was present in the left lower extremity. Superficial sensation was normal, but the sense of vibration was depressed in the lower extremities.

Radiography. Plain radiographs of the cervical spine revealed spondylotic changes at C5-C7. Cervical MRI revealed an intraspinal mass lesion at C7-Th1 and severe compression of the thecal sac (Fig. 1). The lesion had a high intensity on both $\mathrm{T}_{1}-$ and $\mathrm{T}_{2}-$ weighted sequences. Spinal canal stenosis of C3-C7 was found. CT scanning showed that the lesion was located just medial to the right C7-Th1 facet joint and dorsolateral to the spinal cord. A thin calcified rim surrounded the central portion. (Fig. 2). Spinal instability was not apparent.

Surgical resection of the calcified mass and C3-C6 laminoplasty were planned because his neurological condition deteriorated rapidly. 
Spinal paraarticular osteochondroma

Operation. After laminectomy of C7-Th1, an epidural mass lesion was identified dorsolateral to the dura mater (Fig. 3). The lesion was connected to the ligamentum flavum but not to the facet joint or lamina. There was no adhesion between the dura and the lesion, which was resected easily. C3-C6 laminoplasty was also performed. Histological findings. Grossly, the lesion measured $15 \times 9 \times 6 \mathrm{~mm}$, comprised multiple small nodules, and had a cartilaginous surface that was attached to the ligamentum flavum (Fig. 4). Histologically, the lesion comprised lamellar trabecular bone and bone marrow, and was capped by hyaline cartilage (Fig. 5a). Fibroblastic tissue was continuous with both bone and cartilage (Fig. 5b). Endochondral ossification intervened between the bone and cartilage. No feature suggestive of malignancy was found.

Postoperative Course. The patient's muscle weakness and gait disturbance improved dramatically. The complete removal of the tumor and decompression of C3-7 were confirmed on 1 year postoperative MRI (Fig. 6)

\section{Discussion}

The concept of paraarticular osteochondroma was first introduced in 1958 by Jaffe, who used the synonymous terms paraarticular chondroma and intracapsular chondroma to describe osteochondral metaplasia occurring in the fibrous joint capsule or soft tissue 
Spinal paraarticular osteochondroma

adjacent to a joint $[2,9]$. Milgram and Dunn were the first to use the term paraarticular osteochondroma and to differentiate the same lesion from synovial chondromatosis [7].

About 35 cases were reported subsequently in the literature $[3,8,10]$. The knee is the most frequent site $(76 \%)$, followed by the foot $(19 \%)$ and ankle $(5 \%)[3,8]$. Our report is the first on paraarticular osteochondroma arising in the spinal canal just medial to the articular facet joint.

The diagnosis of this tumor is based on the association of radiological and histological features. Reith et al. established the following diagnostic criteria for paraarticular osteochondroma: (1) The lesion presented as a single, dominant mass, both radiographically and grossly. (2) The mass consisted histologically of both bone and cartilage, organized in a manner similar to conventional osteochondromas. (3) The lesion was not intra-articular, that is, it did not arise within the synovium itself [3]. The current case met these criteria.

The pathological findings of paraarticular osteochondroma show certain characteristics $[2,3,7,8]$. The lesion is a well circumscribed, mineralized mass without any direct continuity with the adjacent bone. Grossly, it comprises multiple osteochondral nodules. Histologically, the configuration of each nodule is similar to a conventional osteochondroma. The peripheral portion of each nodule contains cartilaginous areas, 
Spinal paraarticular osteochondroma

whereas the central portion contains lamellar, trabecular bone. Endochondral ossification is evident at the interface between the cartilage and bone. The histological features in the current case were also compatible with the diagnosis.

The differential diagnosis of a mineralized, juxta-facet mass lesion in the spinal canal should include a spinal juxtafacet cyst, spinal osteochondroma, tumoral calcinosis, synovial chondromatosis, and extraskeletal chondrosarcoma. A spinal juxtafacet cyst usually appears as an intraspinal extradural mass arising from the facet joint with degenerative changes. Although rare in the cervical spine, it preferentially involves the cervico-thoracic junction and often presents as myelopathy $[11,12]$. Calcification of the cyst may also be present, but MRI reveals a hypointensity on T1-weighted images and a fluid-filled cystic lesion on T2 sequences [11, 13]. Spinal osteochondroma is characterized by an osseous stalk that is continuous either with the vertebral body, lamina, or pedicle [4-6]. Tumoral calcinosis is a periarticular tumor-like calcified mass that often occurs adjacent to the large joints of the extremities: it arises rarely in the spinal canal, and histologically lacks a cartilage cap [14, 15]. Paraarticular osteochondromas sometimes grow very large and show histological features suggestive of malignancy, including cytological atypia and hypercellularity of the cartilaginous component [3]. Therefore, it is sometimes important to distinguish this tumor from 
Spinal paraarticular osteochondroma

1

2

extraskeletal chondrosarcoma. In the current patient, the tumor was much smaller than those reported in the literature and lacked histological features of a malignancy, possibly because the intraspinal extradural location and presentation of myelopathy led to early detection of the tumor.

Paraarticular osteochondromas are highly amenable to gross total removal and, although reports of follow-up of such cased are limited, no recurrences have been reported.

As with other bone tumors, clinical and radiographic findings and histopathological examination are essential for a correct diagnosis. 
Spinal paraarticular osteochondroma

\section{Conflict of interest}

The authors declare that they have no conflict of interest.

\section{References}

1. Unni KK, Inwards CY. Osteochondroma. In: Dahlin's Bone Tumors. Philadelphia: Lippincott Williams \& Wilkins, 2010: 9-21

2. Maheshwari AV, Muro-Cacho CA, Pitcher JD. Extraskeletal para-articular osteochondroma of the posterior knee. Case report. J Knee Surg 2009; 22: 30-33

3. Reith JD, Bauer TW, Joyce MJ. Paraarticular osteochondroma of the knee. Report of 2 cases and review of the literature. Clin Orthop Relat Res 1997; 334: 225-232

4. Lotfinia I, Vahedi P, Tubbs RS, et al. Neurological manifestations, imaging characteristics, and surgical outcome of intraspinal osteochondroma. J Neurosurg Spine 2010; 12: 474-489

5. Roach JW, Klatt JW, Faulkner ND. Involvement of the spine in patients with multiple hereditary exostoses. J Bone Joint Surg Am 2009; 91:1942-1948

6. Yagi M, Ninomiya K, Kihara M, et al. Symptomatic osteochondroma of the spine in elderly patients. Reports of 3 cases. J Neurosurg Spine 2009; 11: 64-70

7. Milgram JW, Dunn EJ. Para-articular chondromas and osteochondromas: A report of 
Spinal paraarticular osteochondroma

three cases. Clin Orthop Relat Res 1980; 148: 147-151

8. Ratcliff JR, Naqvi A, de la Roza G, et al. Soft tissue osteochondroma; case report and immunohistochemistry for parathyroid hormone-related protein. Ann Diagn Pathol 2006; 10(4): 222-229

9. Jaffe HL. Tumors and timorous conditions of the bones and joints. Philadelphia: Lea and Febiger 1958: 558-567

10. Ozturan KE, Yucel U, Cakici $\mathrm{H}$, et al. Patellar tendinopathy caused by a para-articular/extraskeletal osteochondroma in the lateral infrapatellar region of the knee: a case report. Cases J 2009; 2: 1-4

11. Song JK, Musleh W, Christie SD, et al. Cervical juxtafacet cysts: case report and literature review. Spine J 2006; 6: 279-281

12. Miwa M, Doita M, Takayama H, et al. An expanding cervical synovial cyst causing acute cervical radiculopathy. J Spinal Disord Tech 2004; 17: 331-333

13. Nijensohn E, Russell EJ, Milan M, et al. Calcified synovial cyst of the cervical spine: CT and MR evaluation. J Comput Assist Tomogr 1990; 14(3): 473-476

14. Miyakoshi N, Shimada Y, Kasukawa Y, et al. Progressive myelopathy due to idiopathic intraspinal tumoral calcinosis of the cervical spine. J Neurosurg Spine 2007; 7: 362-365 
Spinal paraarticular osteochondroma

1

2

3

4

5

6

7

8

9

10

11

12

13

14

15

16

17

18

19

20

21

22

23

24

25

26

27

28

29

30

31

32

33

34

35

36

37

38

39

40

41

42

43

44

45

46

47

48

49

50

51

52

53

54

55

56

57

58

59

60

61

62

63

64

65

15. Flores J, Gallego JM, Bujan A, et al. Spinal cord compression due to tumoral idiopathic calcinosis. Spinal Cord 2003; 41: 413-416 
Spinal paraarticular osteochondroma

\section{Figure Legend}

Fig. 1. Intraspinal mass lesion at C7-T1 with severe compression of the spinal cord was seen in sagittal T1-weighted (a), sagittal T2-weighted (b), and coronal T2-weighted (c) MR images. Spinal canal stenosis on C3-C7 was found concomitantly.

Fig. 2. CT scanning showing the calcified lesion located just medial to the right C7-T1 facet joint and dorsolateral to the spinal cord (arrow).

Fig. 3. After laminectomy of C7-T1, an epidural mass lesion was identified dorsolateral to the dura mater (arrow).

Fig. 4. Gross specimen showing multiple small nodules and a cartilaginous surface attached to the ligamentum flavum (arrow).

Fig. 5. (a) Microscopic examination showing lamellar trabecular bone and bone marrow capped by hyaline cartilage. (Hematoxylin and eosin stain)

(b) The fibroblastic tissue was continuous with both the bone and cartilage (arrows).

(Hematoxylin and eosin stain)

Fig. 6. One year postoperative MR imaging. The complete removal of the tumor and decompression of C3-7 were confirmed. 


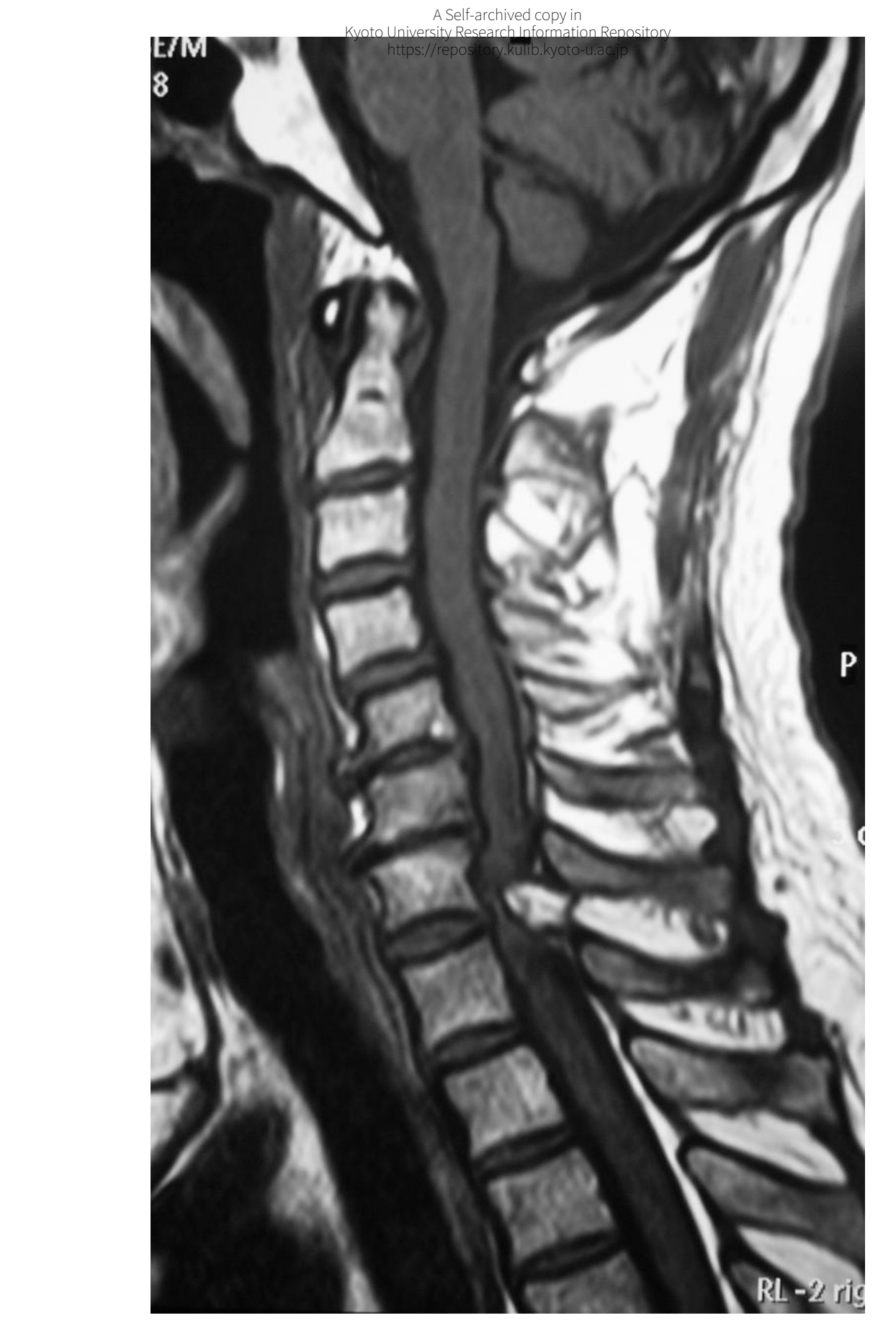

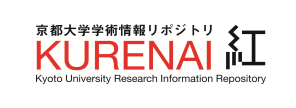

\section{(1)}

(




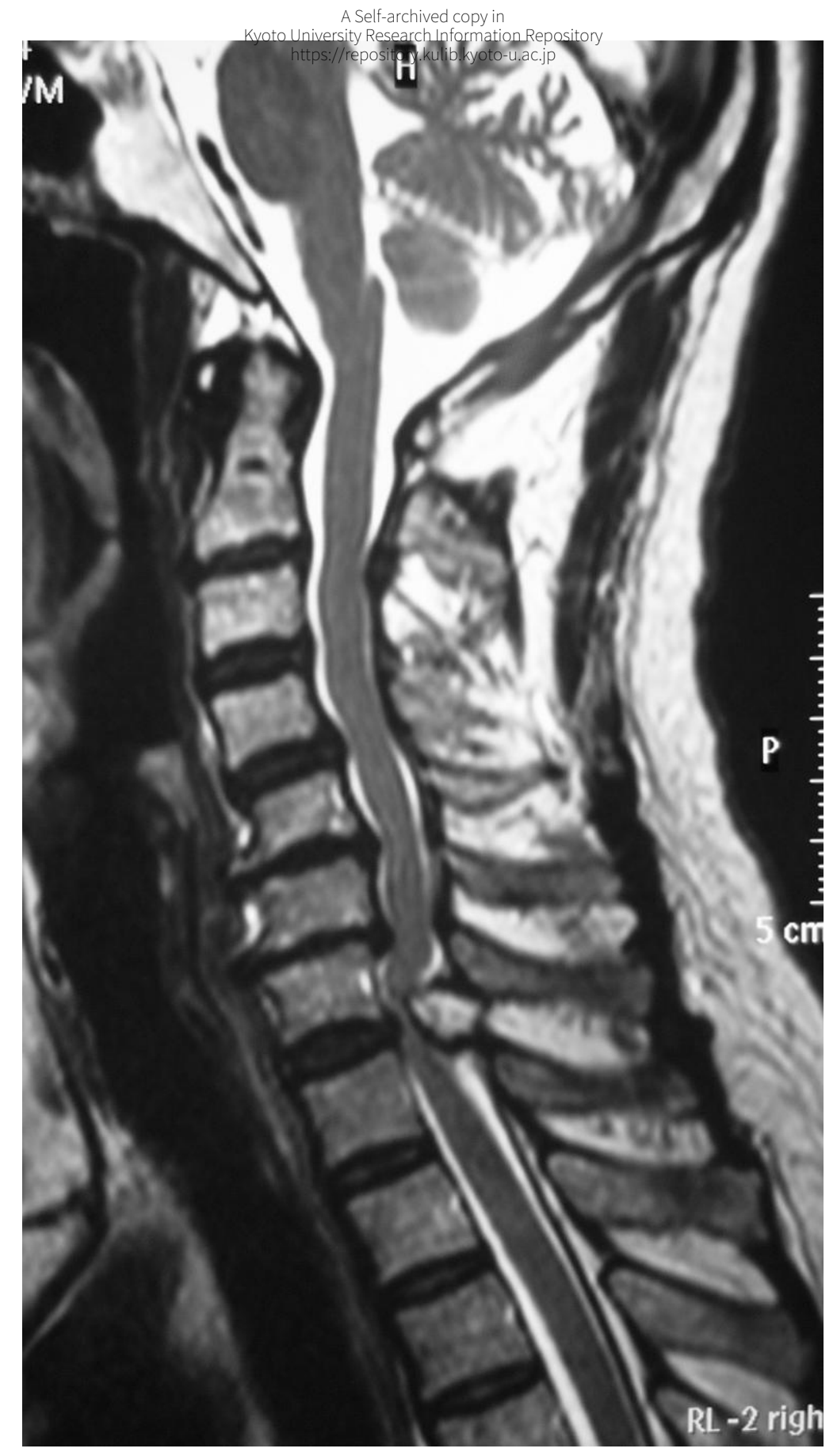

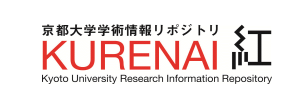
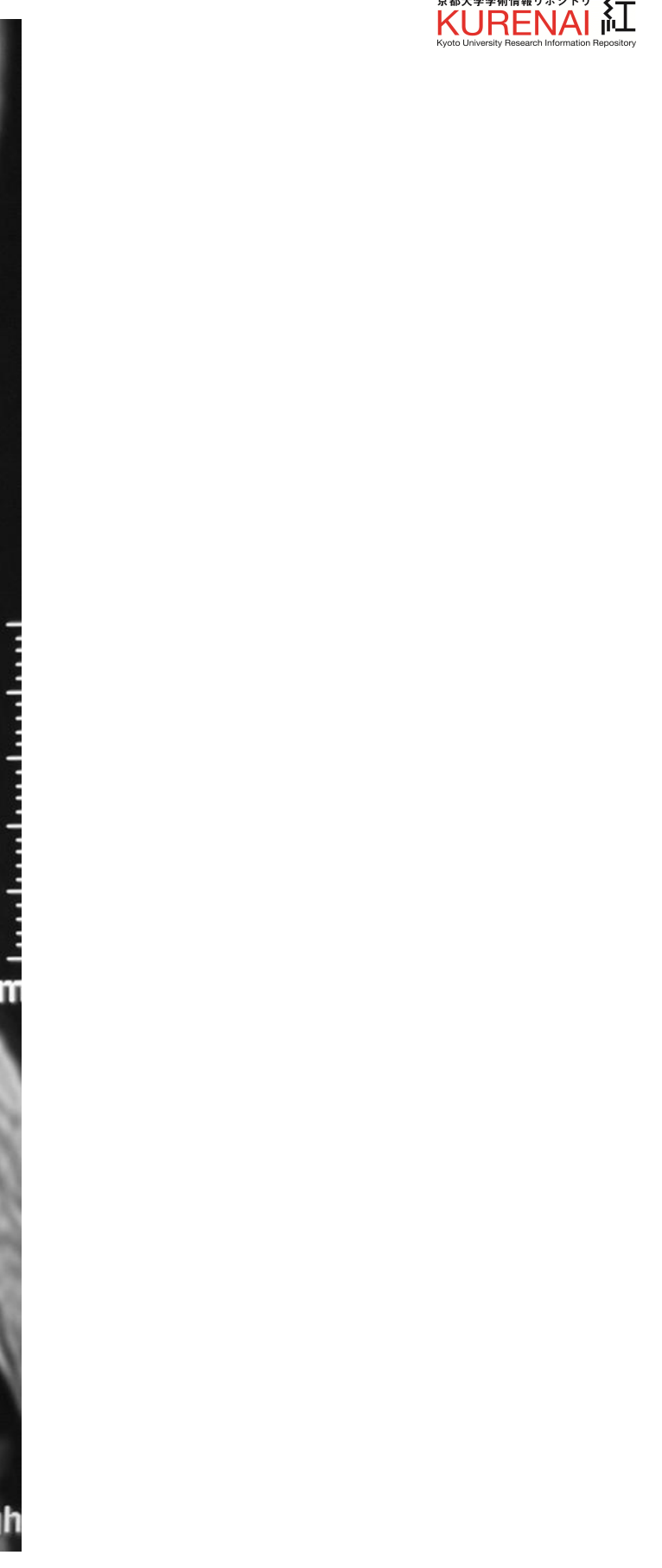


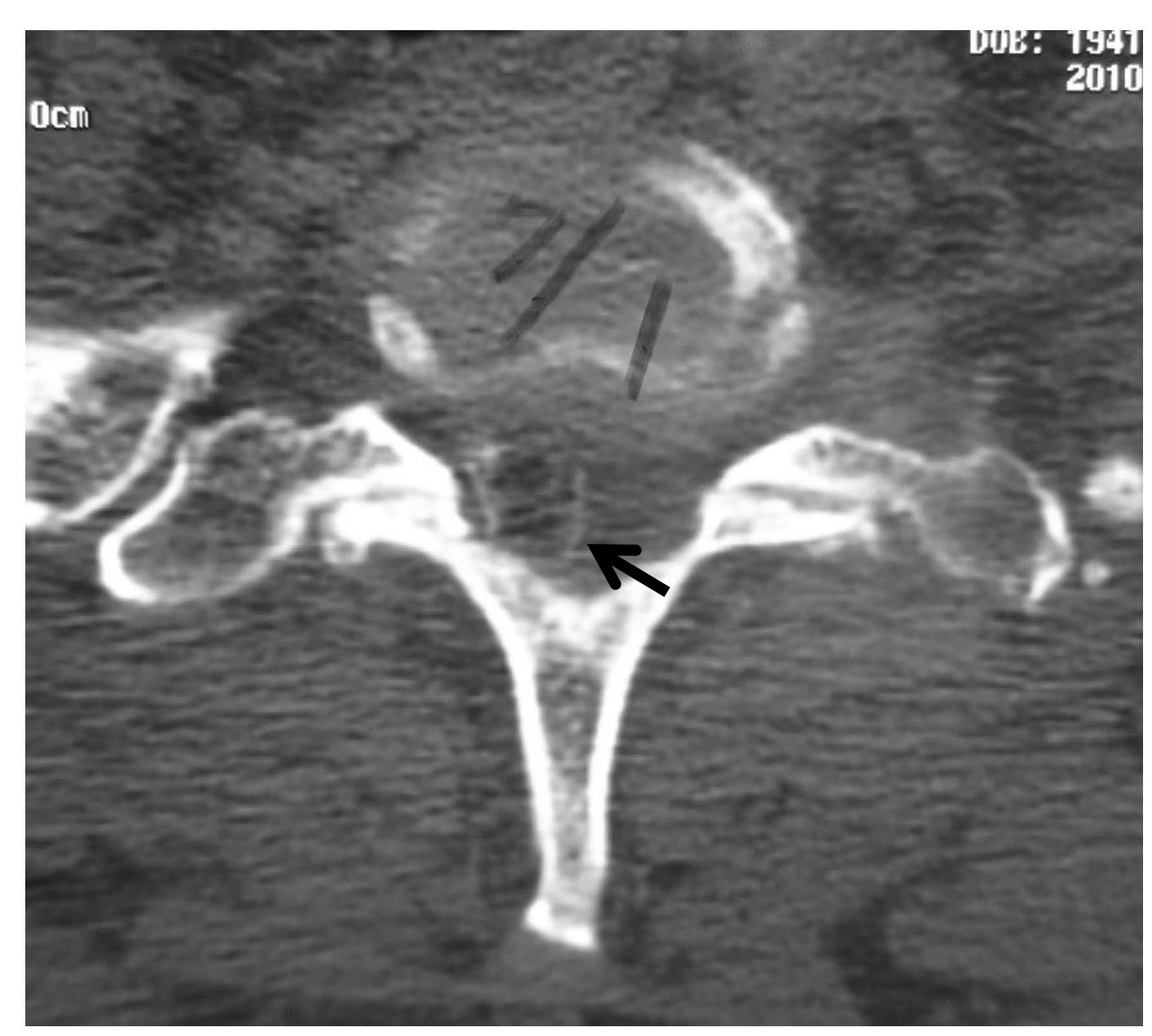

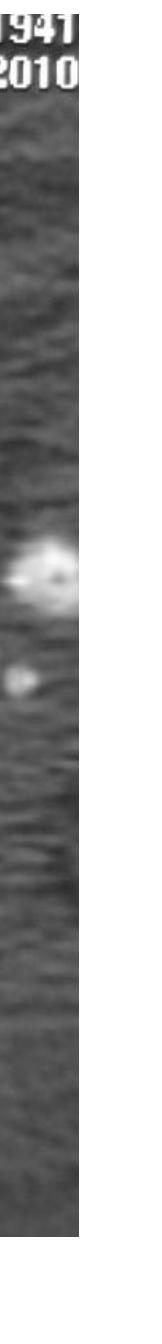





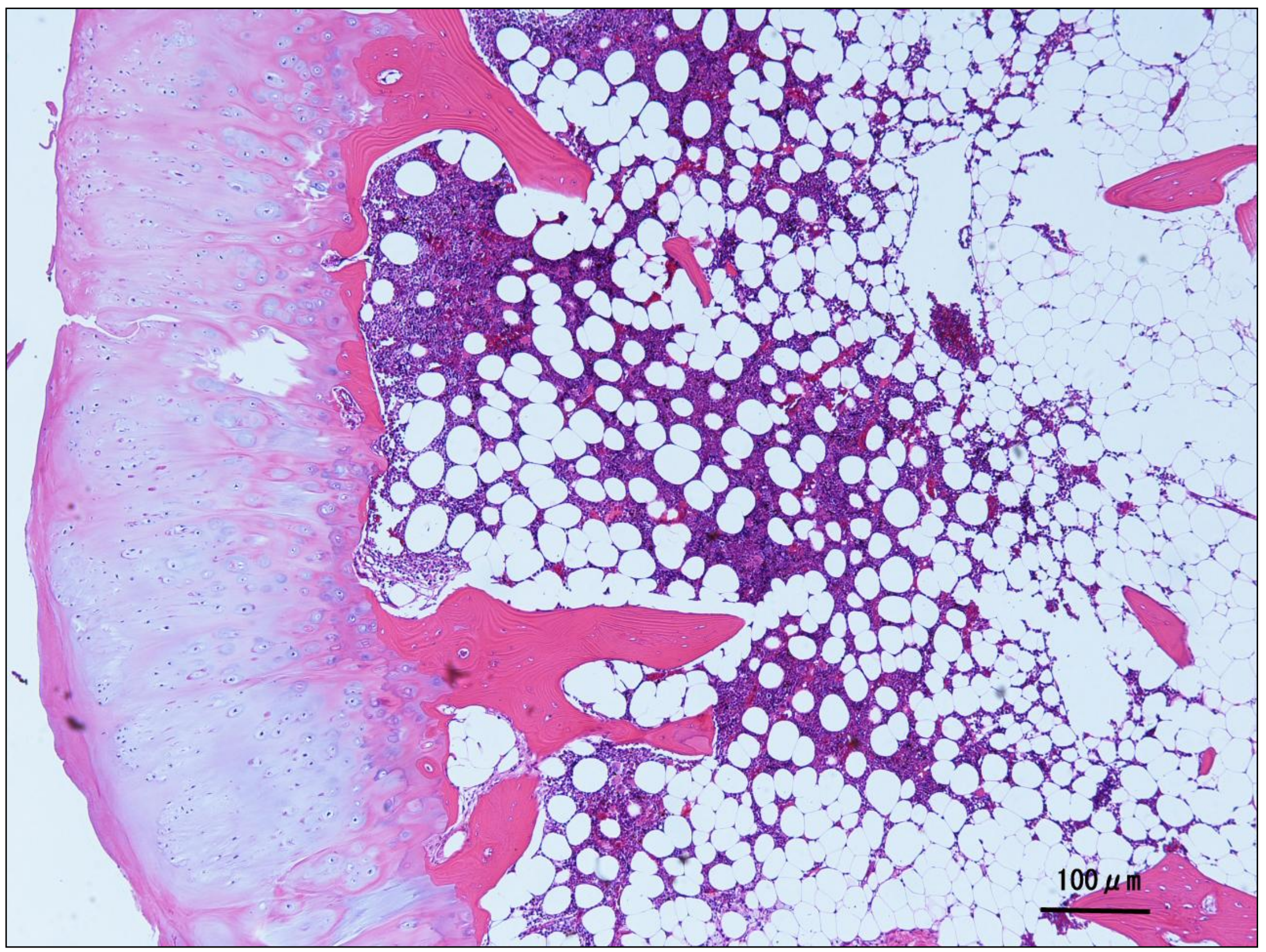




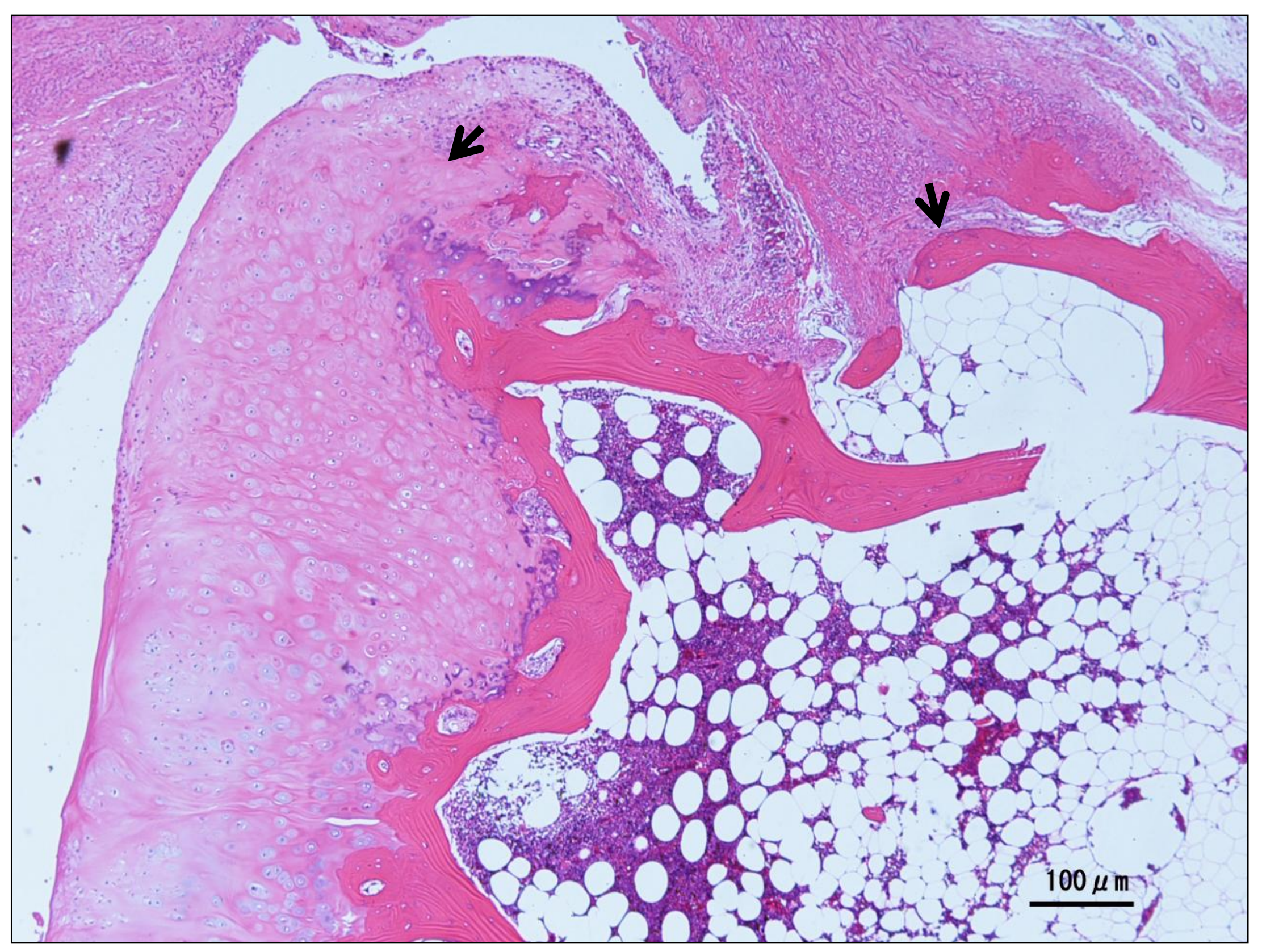


